\title{
Effect of Roll Gap Setup on Shape Defects during a Flexible Roll Forming Process
}

\author{
Young Yun Woo, Tae Woo Hwang, Sang Wook Han and Young Hoon Moon* \\ School of Mechanical Engineering, Pusan National University, 30 Jangjeon dong, Geumjeonggu, Busan, 609-735, Republic of Korea
}

\begin{abstract}
The flexible roll forming process is an advanced sheet metal forming process which manufactures parts with variable cross-section profiles. The metal sheet is incrementally bent into the desired shape by passing it through successive roll stands. In this process, contacts of the flange and web sides are controlled by roll gaps in vertical and horizontal directions. To investigate the effect of the roll gap on shape defects during the flexible roll forming process, experiments were conducted using a lab-scale machine according to different combinations of roll gapsetups: 1) a smaller flange gap than the blank thickness; 2) the same flange and web gaps as the blank thickness; 3) a smaller web gap than the blank thickness. Three kinds of symmetric blanks with trapezoid, concave and convex shapes were used for the experiments. To investigate the effect of the roll gap on shape defects, web-warping and longitudinal strain at the edge for the three different blank shapes were characterized at various combinations of roll gap setups. [doi:10.2320/matertrans.MT-ML2019012]
\end{abstract}

(Received August 5, 2019; Accepted September 26, 2019; Published November 1, 2019)

Keywords: flexible roll forming, roll gap, shape defect, web-warping, longitudinal strain

\section{Introduction}

During the roll forming process, an initial metal blank is transformed into the desired profile with continuous bending through a series of forming rolls. The conventional roll forming process is available to manufacture the parts of constant profile with long length in large quantities at high production rates. ${ }^{1,2)}$ However, in many industries such as the automotive industry, ship construction, and aerospace engineering, demands for the parts with variable profile has been increased to reduce the weight and increase functionality. ${ }^{3-9)}$

Flexible roll forming is a new forming process that allows the manufacture of parts with a variable profile. In this process, the rolls are not fixed at their position but can move both axially and rotationally along a trajectory so that can produce parts with the variable profile. During flexible roll forming, metal blanks are subjected to three-dimensional deformation such as transverse bending and other redundant deformations which includes inhomogeneous elongations or contraction at the blank. These redundant deformations can cause shape defects, such as camber, web warping, twist, and wrinkling. ${ }^{10-12)}$ Previous research has investigated the effect of the longitudinal strain of strip edge during flexible roll forming process on defects such as bow and edge wave. Woo et al. characterized the degree of web-warping for different blank shapes and materials. ${ }^{13-15)}$ They introduced the leveling roll to reduce the web-warping during the flexible-roll-forming process. Their result showed that the web-warping can be reduced by applying the leveling roll. Safdarian and Moslemi Naeini investigated the effects of the roll forming parameters of a channel section on the web-warping and longitudinal strain. ${ }^{16)}$ Their result showed that peak longitudinal strain at the edge increases with increasing bending angle increment, strip thickness, however, the friction coefficient and speed of the roll do not have any effect on the longitudinal strain at the edge. Kasaei et al. investigated wrinkling limits in the flexible roll forming process using the experimental and numerical simulation. ${ }^{17}$ )

*Corresponding author, E-mail: yhmoon@pusan.ac.kr
They predicted the occurrence of flange wrinkling in variable cross-sectional profiles via the combined evolution of the effective strain and stress triaxiality. Groche et al. developed an analytical one-step model to produce wrinkling-free parts with flexible roll forming. ${ }^{18)}$ Their model is semi-empirical and based on plate-buckling mechanics to investigate the feasibility of new profile geometries without wrinkling. Wiebenga et al. studied bowing and springback defect in advanced high strength steel with V-shaped sections using a robust optimization method based on experiment and numerical analysis. ${ }^{19)}$ Bowing and springback defects are reduced with the decreasing gap between forming rollers in each stand. Paralikas et al. introduced an optimization procedure for the roll forming process. ${ }^{20)}$ They investigated the effect of distance between forming stands, forming rate, the gap between roller pairs in each stand, and roller diameter on the shear and longitudinal strains that occur on the flanges of products. Their result showed that the interdistance between two successive stands and the gap between roller pairs in each stand is most effective for improving the quality.

Most previous studies have focused on the effect of the vertical roll gap on shape defects of the roll-formed part. However, the studies on the effect of the flange and web gaps on shape defects were generally lacking and scarce. Therefore, the effect of the flange and web gaps on shape defects in flexible roll forming process was experimentally investigated in this study. We investigated web-warping and longitudinal strain for three different blank shapes at various combinations of setup roll gaps.

\section{Experiment}

Experiments were carried out using the laboratory-scale flexible roll forming machine shown in Fig. 1(a). Accurate roll gap control directly affects the product quality and operational performances. ${ }^{21-25)}$ To obtain reproducible data, we ensured that the forming machine consisting of the forming roll stand and leveling roll stand was precisely operated. The leveling roll stand assists the blank to move straight without interfering with the motion of the forming 


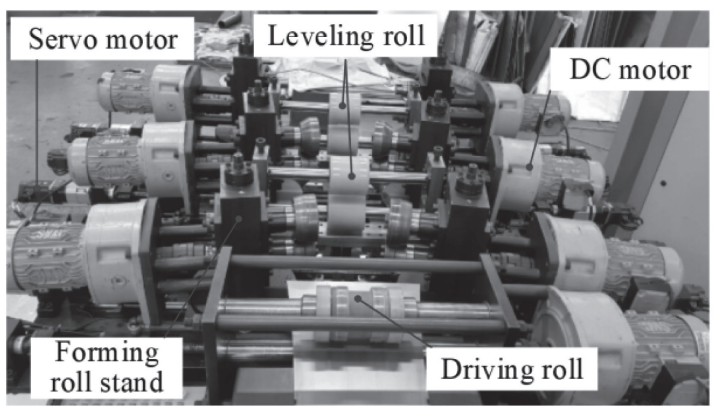

(a)

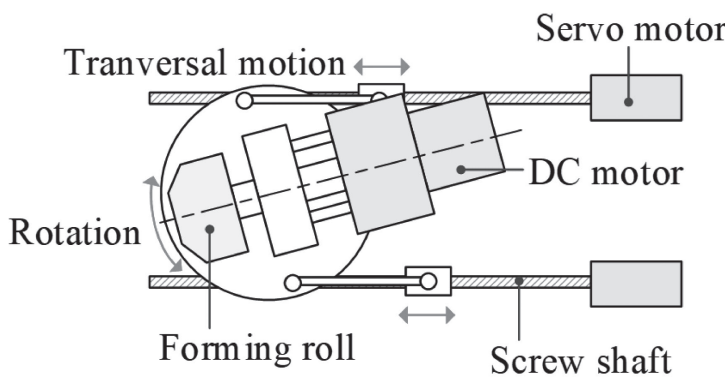

(b)

Fig. 1 (a) Lab-scale flexible roll forming machine and (b) schematic of roll movement.

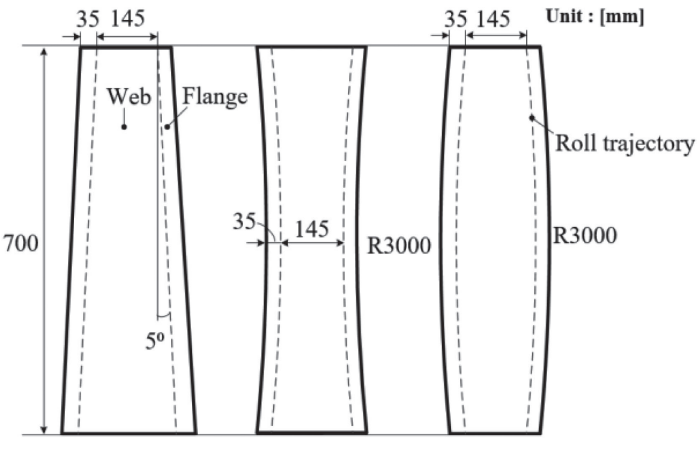

(a)

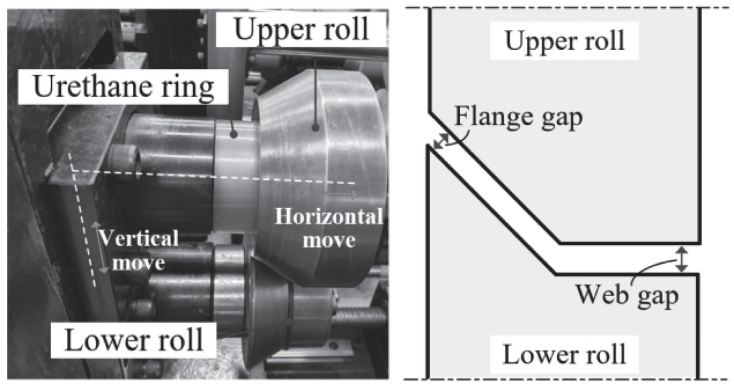

(b)

Fig. 2 (a) Dimensions of the three different blanks: trapezoidal, concave, convex and (b) the flange and the web gap.

Table 1 Flange and web gap setting in the experiment.

\begin{tabular}{ccc}
\hline Combination & Flange gap & Web gap \\
\hline Case 1 & $0.79 \mathrm{~mm}$ & $0.80 \mathrm{~mm}$ \\
Case 2 & $0.80 \mathrm{~mm}$ & $0.80 \mathrm{~mm}$ \\
Case 3 & $0.80 \mathrm{~mm}$ & $0.79 \mathrm{~mm}$ \\
\hline
\end{tabular}

roll. The forming and driving rolls are driven by a DC motor. The driving rolls feed the blank into the forming roll stands. The forming roll stand is connected to a screw shaft which is controlled by a servo motor so that the forming roll stands move and rotate according to a variable roll trajectory as shown in Fig. 1(b).

The bland was fed to the forming roll stand at a speed of $4.6 \mathrm{~mm} / \mathrm{s}$ by the driving roll, and the forming roll had a $30^{\circ}$ bending angle. We used three different blanks with trapezoidal, convex, and concave shapes with a $0.8 \mathrm{~mm}$ thickness in the experiments as shown in Fig. 2(a). Test material was SPCC mild steel with a Young's modulus of $207 \mathrm{GPa}$, a yield strength of $170 \mathrm{MPa}$, an ultimate tensile strength of $339 \mathrm{MPa}$, and an elongation of $33.2 \%$.

To investigate the effect of roll gaps on the flexible roll forming process, we controlled the flange and web gaps as shown in Fig. 2(b). The web gap can be controlled from $0 \mathrm{~mm}$ to $2 \mathrm{~mm}$ by changing the vertical position of the upper forming. To control the flange gap, a urethane ring was introduced to the forming roll shaft as shown in Fig. 2(b) so that the horizontal position of the upper roll could be controlled until the urethane ring could be compressed. The three combinations of setup roll gaps implemented in this study are summarized in Table 1.

To better understand the flexible roll forming process, the longitudinal strain history at the edge was measured experimentally via a resistance strain gauge. A strain gauge was mounted at the edge of the blank, and the strain was measured using the data logger and notebook computer as shown in Fig. 3.

\section{Results and Discussions}

Figure 4 shows the formed blanks obtained from the flexible roll forming experiments. As shown in the figures, there was a web-warping defect but no wrinkling. To 


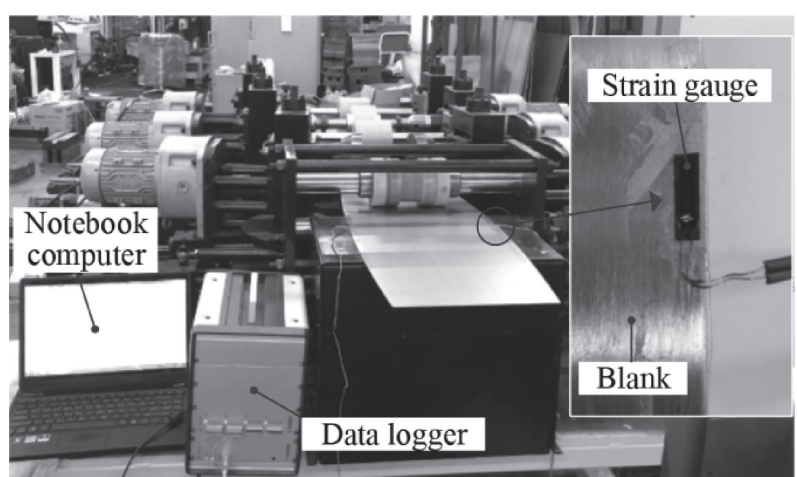

Fig. 3 Experiment setup for measurements of longitudinal strain.

investigate the web-warping at various setup roll gaps quantitatively, we defined the web-warping height as the maximum deviation in the height of the web area over the length of the profiles as shown in Fig. 5(a). Figure 5(b) shows the web-warping heights obtained from experiments. This result indicates that Case 1 increased the web-warping height while Case 3 decreased the web-warping height.

During flexible roll forming, the flange zone needs to be longitudinally stretched in the concave blank and compressed in the convex blank for a flat web part. ${ }^{26,27)}$ The required strains can be calculated via eqs. (1) and (2) as shown in Fig. 6.

$$
\begin{array}{cl}
\varepsilon_{\text {convexblank }}=\ln \left(\frac{R_{1}^{\prime}}{R_{1}}\right) \frac{\theta_{\text {bend }}}{90^{\circ}}, & R_{1}^{\prime}=R_{1}-F \\
\varepsilon_{\text {concaveblank }}=\ln \left(\frac{R_{2}^{\prime}}{R_{2}}\right) \frac{\theta_{\text {bend }}}{90^{\circ}}, & R_{2}^{\prime}=R_{2}+F
\end{array}
$$

where $\theta_{\text {bend }}$ is the bend angle, $F$ the flange width, and $R$ the blank radius.

According to eq. (1) and eq. (2), the required analytical longitudinal strains are -0.00391 for the convex blank and 0.00387 for the concave blank; $F$ is $35 \mathrm{~mm} ; R_{1}$ and $R_{2}$ are $3000 \mathrm{~mm}$, and $\theta_{\text {bend }}$ is $30^{\circ}$. If the required longitudinal deformation is insufficient, different web-warping can occur to compensate for the required deformation so that the concave blank bends downward, whereas the convex blank bends upward as shown in Fig. 7.

Figure 8 shows the longitudinal strain history of three different blank shapes with different roll gap setups. Peak longitudinal strains for cases 1,2 and 3 are $7.7 \times 10^{-3}$, $6.1 \times 10^{-3}, 6.0 \times 10^{-3}$ for a trapezoidal blank, $8.4 \times 10^{-3}$, $6.9 \times 10^{-3}, 7.0 \times 10^{-3}$ for a concave blank and $6.4 \times 10^{-3}$, $5.5 \times 10^{-3}, 5.5 \times 10^{-3}$ for a convex blank. This result indicates that a smaller flange gap induced an excessive longitudinal strain at the edge and causes web-warping. In the case of smaller web gap, the peak longitudinal did not change significantly, but the web-warping decreased. A smaller web gap induced longitudinal strain at the web part,

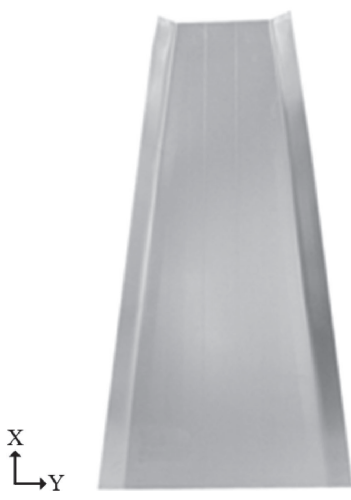

(a)

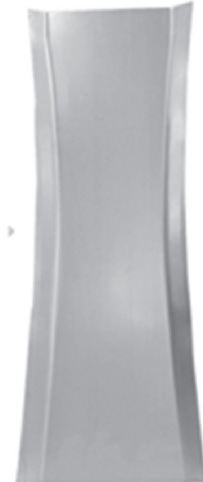

(b)
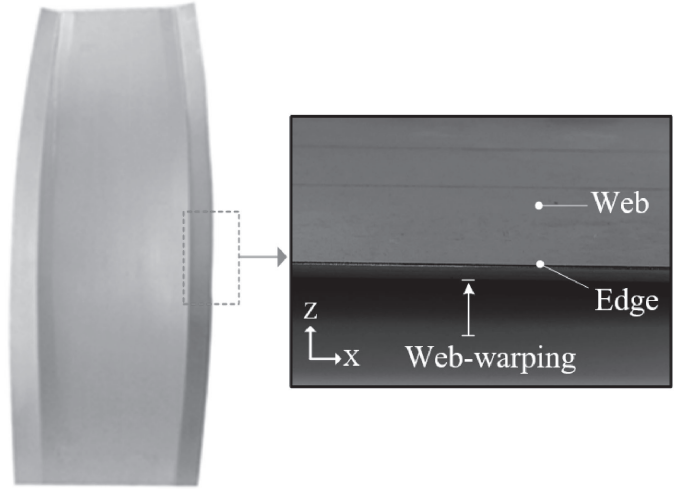

(c)

Fig. 4 Experimental result; (a) trapezoidal, (b) concave, (c) convex blanks.

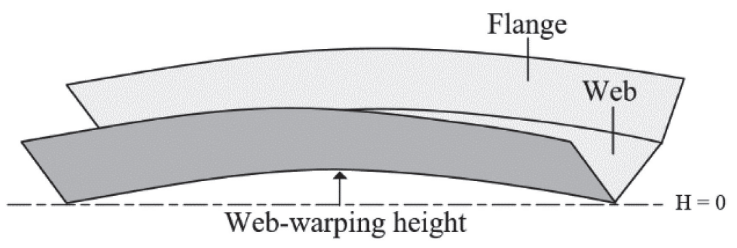

(a)

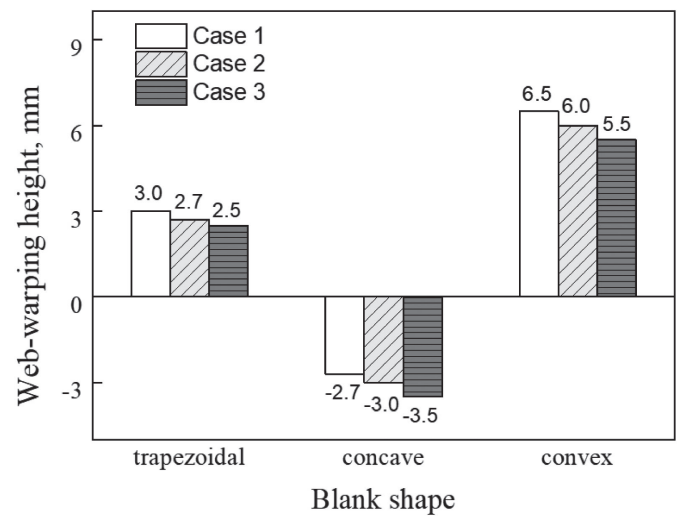

(b)

Fig. 5 (a) Measurement of web-warping, (b) experimental web-warping heights. 


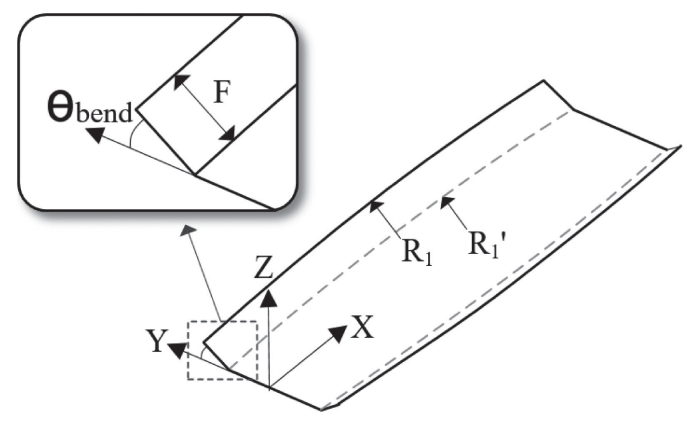

(a)

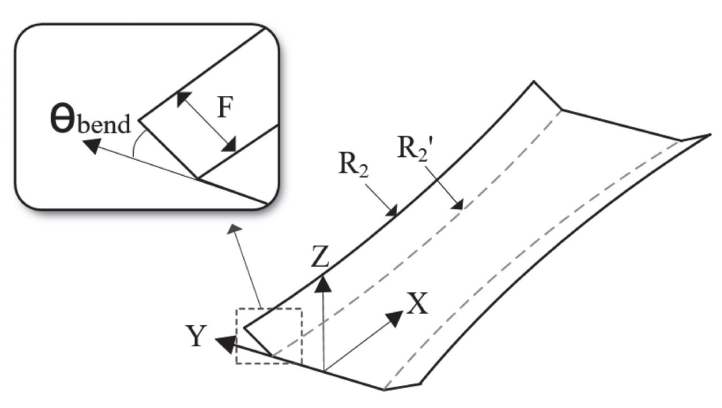

(b)

Fig. 6 Schematics of (a) convex blank and (b) concave blank.

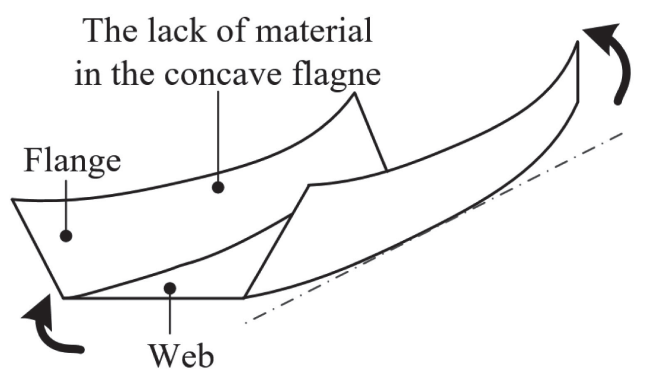

(a)
The surplus of material in the convex flagne

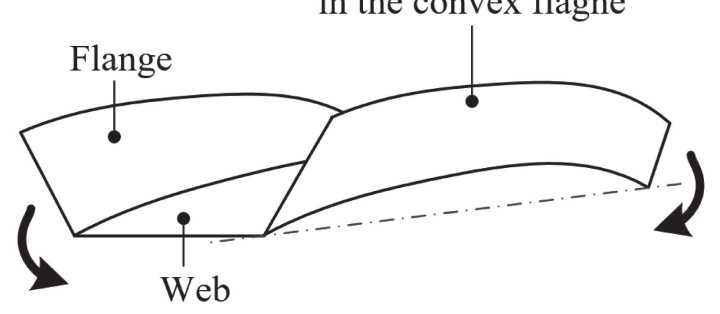

(b)

Fig. 7 Schematics of (a) downward and (b) upward web-warping.

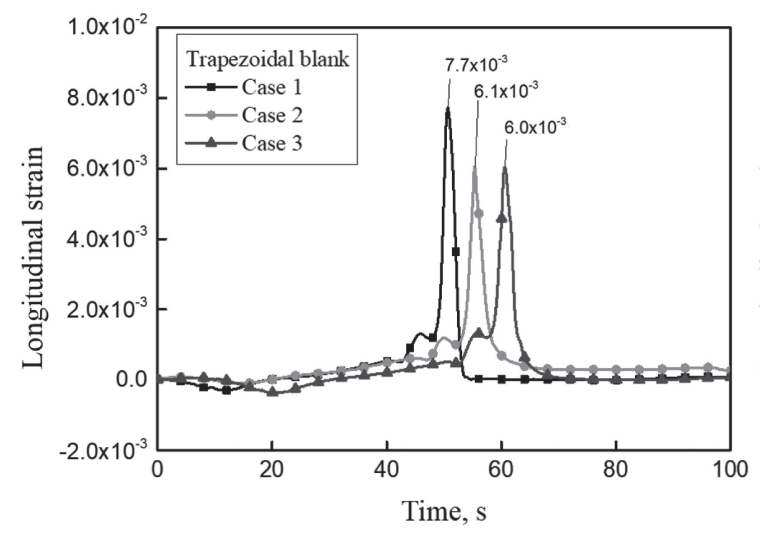

(a)

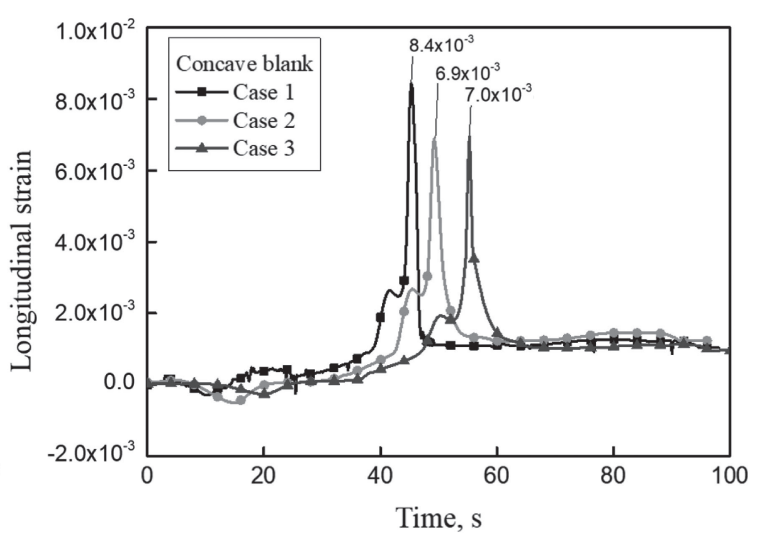

(b)

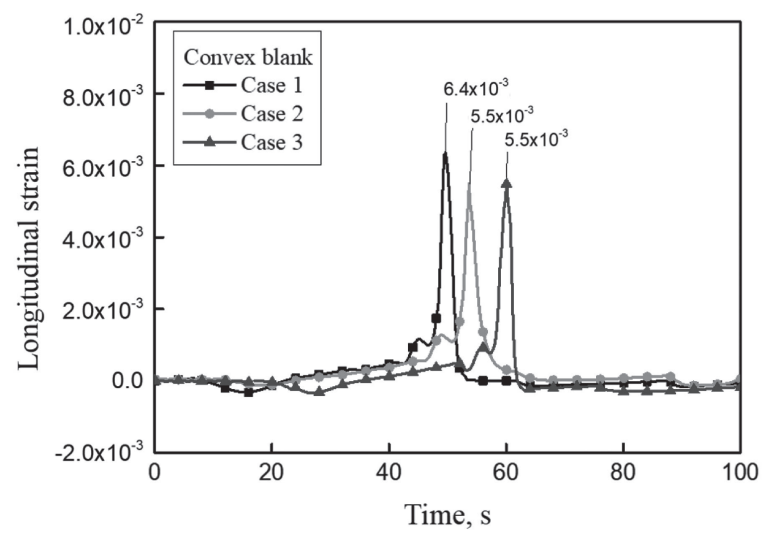

(c)

Fig. 8 Longitudinal strain history at the edge with different roll gap setup of (a) trapezoidal, (b) concave, and (c) convex blanks. 
which decreased the non-uniformity of the transversal distribution of the longitudinal strain and resulted in reduced web-warping. A previous study reported that as long as the roll gap was larger than the nominal material thickness, the material was only bent between the rolls, but for a smaller roll gap, the material was coined between the rolls. Due to the coining effect, the bottom part was elongated and webwarping was reduced. ${ }^{19)}$

\section{Conclusion}

We experimentally investigated the effects of flange and web gaps on shape defects and made the following conclusions:

(1) A flange gap smaller than the blank thickness affects both longitudinal strain and web-warping. The peak longitudinal strain at the edge and the web-warping height increase with a smaller flange gap.

(2) A web gap smaller than the blank thickness affects the web-warping but not so much for the longitudinal stain at the edge. The web-warping height decreases with a smaller web gap.

(3) For trapezoidal and convex blanks, web-warping was reduced with a smaller web gap. For a concave blank, web-warping was reduced for a smaller flange gap because the convex flange was compressed while the concave flange was stretched for the flat web part.

\section{Acknowledgement}

This research was supported by Basic Science Research Program through the National Research Foundation of Korea (NRF) funded by the Ministry of Education (No. 2016R1D1A3B03931174).

\section{REFERENCES}

1) S.M. Panton, S.D. Zhu and J.L. Duncan: Int. J. Mech. Sci. 36 (1994) $725-735$.

2) K. Sweeney and U. Grunewald: J. Mater. Process. Technol. 132 (2003) 9-15.

3) C.H. Jeon, S.W. Han, B.D. Joo, C.J. Van Tyne and Y.H. Moon: Met.
Mater. Int. 19 (2013) 1069-1076.

4) S.Y. Kim, B.D. Joo, S.G.R. Shine, C.J. Van Tyne and Y.H. Moon: Int. J. Mach. Tools Manuf. 68 (2013) 56-62.

5) B.H. Kang, M.Y. Lee, S.M. Shon and Y.H. Moon: J. Mater. Process. Technol. 194 (2007) 1-6.

6) S.W. Han, Y.Y. Woo, T.W. Hwang, I.Y. Oh and Y.H. Moon: Int. J. Mach. Tools Manuf. 138 (2019) 51-65.

7) S.M.H. Seyedkashi, R.V. Panahizadeh, H.B. Xu, S.Y. Kim and Y.H. Moon: J. Mech. Sci. Technol. 27 (2013) 169-175.

8) M. Sato, M. Mizumura, T. Yoshida, Y. Kuriyama, K. Suzuki and A. Tomizawa: Mater. Trans. 60 (2019) 538-543.

9) Y.-G. Kim, M.-H. Kim and S.-M. Joo: Mater. Trans. 59 (2018) 14461451.

10) G. Halmos: Roll Forming Handbook, (CRC Press, USA, 2005).

11) Y.H. Moon, D.W. Kim and C.J. Van Tyne: Int. J. Mech. Sci. 50 (2008) 666-675.

12) R. Kakinoki, Y. Segawa, Y. Marumo, Y. Imamura, T. Nonaka and Y. Sakata: Mater. Trans. 59 (2018) 799-804.

13) Y.Y. Woo, S.W. Han, T.W. Hwang, J.Y. Park and Y.H. Moon: J. Mater. Process. Technol. 252 (2018) 782-794.

14) J.H. Kim, Y.Y. Woo, T.W. Hwang, S.W. Han and Y.H. Moon: J. Mech. Sci. Technol. 30 (2016) 5633-5639.

15) Y.Y. Woo, S.W. Han, I.Y. Oh and Y.H. Moon: Int. J. Automot. Technol 20 (2019) 227-236.

16) R. Safdarian and H.M. Naeini: Thin-Walled Struct. 92 (2015) 130136.

17) M.M. Kasaei, H.M. Naeini, G.H. Liaghat, C.M.A. Silva, M.B. Silva and P.A.P. Martins: J. Strain Anal. Eng. Des. 50 (2015) 528-541.

18) P. Groche, A. Zettler, S. Berner and G. Schneider: Int. J. Mater. Form. 4 (2011) 371-377.

19) J.H. Wiebenga, M. Weiss, B. Rolfe and A.H. van den Boogaard: J. Mater. Process. Technol. 213 (2013) 978-986.

20) J. Paralikas, K. Salonitis and G. Chryssolouris: Int. J. Adv. Manuf. Technol. 47 (2010) 1041-1052.

21) H.K. Yi, D.W. Kim, C.J. Van Tyne and Y.H. Moon: Proc. Inst. Mech. Eng., Part C 222 (2008) 117-129.

22) J.H. Jang, B.D. Joo, C.J. Van Tyne and Y.H. Moon: Met. Mater. Int. 19 (2013) 497-506.

23) Y.-H. Moon, E.-S. Lee and J.-W. Park: Int. J. Adv. Manuf. Technol. 20 (2002) 720-726.

24) J.H. Jang, J.H. Lee, B.D. Joo and Y.H. Moon: Trans. Nonferrous Met. Soc. China 19 (2009) 913-916.

25) T.D. Kil, J.M. Lee and Y.H. Moon: J. Mater. Process. Technol. 220 (2015) 224-230.

26) J. Jiao, B. Rolfe, J. Mendiguren and M. Weiss: Int. J. Mech. Sci. 90 (2015) 228-238.

27) J. Jiao, B. Rolfe, J. Mendiguren and M. Weiss: Int. J. Adv. Manuf. Technol. 86 (2016) 1541-1555. 